\title{
A cidade e a construçáo sociopolítica do planejamento urbano-tecnológico
}

Rodrigo Firmino. Pontifícia Universidade Católica do Paraná, Curitiba, Brasil. Klaus Frey. Universidade Federal do ABC, Santo Andre, Brasil.

Resumen | O avanço do uso das Tecnologias da Informação e Comunicação (tics) vem se manifestando com força no planejamento e gestão das cidades. Enquanto tradicionalmente o processo da construção sociopolítica das tecnologias urbanas segue uma lógica setorial e fragmentada, ganha relevância a percepção da necessidade de estratégias mais integradas de desenvolvimento urbano e tecnológico. Para uma compreensão desta possível necessidade, é preciso reconstruir fatos e episódios da história de implantação das tics a partir dos grupos sociais envolvidos, de seus interesses e atuaçóes específicas, e a relação entre todos esses aspectos. Este tipo de análise leva em consideraçáo a teoria da construção social das tecnologias, e tem como objetivo produzir uma narrativa dos casos estudados do ponto de vista de sua construção social e política. Assim, neste trabalho analisamos criticamente diferentes estratégias urbanas de apropriação dos avanços tecnológicos - relacionados às TICs - e suas características, bem como o processo sociopolítico de sua formulação.

PALAVRAS-CHAVE | desenvolvimento urbano, gestão urbana, tecnologias da informação e comunicação.

ABSTRACT | The use of Information and Communication Technologies (ICT) has been rapidly growing in the fields of urban planning and management. While, traditionally, the process of sociopolitical construction of urban technologies follows a sectorial and fragmented logic, now there is a growing need for a more comprehensive approach with integrated urban strategies. For an understanding of this possible need, we must rebuild the history of facts and episodes of ICTS deployment from the point of view of the social groups involved, their interests and specific activities, and relationships between all these aspects. This type of analysis takes into consideration the theory of social construction of technology, in order to produce a historical narrative of the case studies, from the perspective of social and political construction. Thus, in this paper, we analyze critically different urban strategies of ICT appropriation and their characteristics, as well as the sociopolitical process in which they have been created.

KEY WORDS | urban development, urban management, information and communication technologies.

Recibido el 31 de octubre de 2011, aprobado el 20 de noviembre de 2012

E-mail: Rodrigo Firmino, rodrigo.firmino@pucpr.br.| Klaus Frey, klaus.frey@ufabc.edu.br

As discussóes presentes neste trabalho foram apresentadas no XIII Encontro Nacional da ANPUR, Florianópolis, em maio de 2009. Os autores gostariam de expressar sua gratidáo à FAPESP por financiar, entre os anos de 2004 a 2007, a pesquisa que deu origem a este artigo. 


\section{Introduçáo}

A difusão massiva nos últimos, anos do grupo de tecnologias conhecido como Tecnologias da Informação e Comunicação (TICs), tem estimulado reflexôes sobre as relaçôes entre espaço, tempo, tecnologias e as possibilidades de sua gestão. Um aspecto decisivo sobre o desafio de compreender as maneiras pelas quais as TICS influenciam a organização do espaço e da vida contemporânea, é o reconhecimento da necessidade de políticas públicas, baseadas em estratégias administrativas locais, para o uso, implementação e gestão do desenvolvimento dessas tecnologias nas cidades. Assim, atenção especial deve ser dada a alguns dilemas cruciais no que diz respeito à promoção e construção sociopolítica dessas estratégias. A identificação desses dilemas pode ser útil para futuras intervençóes, no sentido de promover políticas de caráter democrático e mais integradas de desenvolvimento urbano e tecnológico, e que sejam mais eficientes e adaptadas às diversidades de distintas localidades, buscando maior responsabilidade das políticas em consonância com as demandas locais existentes.

Neste artigo, pretende-se evidenciar esses processos de apropriação das tecnologias na gestão urbana a partir do entendimento de quatro casos específicos de cidades que fizeram, durante um período determinado, uso de projetos e estratégias que envolveram a aplicaçáo das TiCs, para a melhoria ou transformaçáo de processos internos e gerais, em açóes dos governos locais na gestáo urbana. Para esta análise, o trabalho não somente utiliza como inspiração, mas se apropria de abordagens apresentadas pela teoria conhecida como construção social das tecnologias (social construction of technologies ou SсOT, do original em inglês), para construir as narrativas dos casos estudados, a partir da valorizaçáo de fatos e artefatos ${ }^{1}$ presentes nos períodos analisados. Assim, aspectos sociais e políticos de cada uma dessas quatro breves histórias puderam ser levantados, e analisados, para a construção de uma narrativa que estamos chamando de sociopolítica.

Por outro lado, o aspecto específico analisado nesses casos respeita o foco no desenvolvimento urbano-tecnológico. O desenvolvimento integrado das TICs no contexto urbano, tem recebido mais atenção desde o trabalho pioneiro de Graham e Marvin, Telecommunications and the city: electronic space, urban places (1996), com ênfases em averiguar possibilidades de integração de análises, métodos de controle e políticas de inserção das TiCs no espaço urbano, e as implicaçóes para sua gestáo.

Entretanto, tem-se conhecimento de açóes apenas isoladas na busca por integração entre políticas e projetos que envolvam Tics - desde o ponto de vista operacional/ferramental, até sua apropriação como interface de interpretação, percepção e atuaçáo no espaço urbano- e políticas diretamente relacionadas ao controle e desenvolvimento do território urbano. O planejamento urbano ainda tem que romper com a ideia preconcebida de uma disciplina especial, com pouca ou nenhuma consideração a outros setores do desenvolvimento urbano. É nessa direção para qual

1 Apesar de ter sido apresentada inicialmente por Wiebe Bijker (1987) como Social Construction of Technologies, em um artigo publicado alguns anos mais tarde, Trevor Pinch e Wiebe Bijker (1989) utilizam o título Social Construction of Facts and Artifacts, indicando que a abordagem teórica desenvolvida originalmente para compreensão de processos de desenvolvimento tecnológico poderia, na verdade, ser utilizada para a reconstituição de histórias mais abrangentes. 
apontam os resultados de quatro estudos de caso - realizados entre os anos de 2003 e 2006 (com análise documental e realização de entrevistas em todas as cidades) - sobre a construção sociopolítica do desenvolvimento urbano-tecnológico em cidades médias do Brasil e da Europa. Esta pesquisa concentrou-se nas maneiras com que os diferentes governos locais se apropriaram das Tics (como instrumento de gestão e planejamento) e de questôes relacionadas ao desenvolvimento urbano de uma cidade cada vez mais dependente das tecnologias -em um meio técnico-científicoinformacional, diria Santos (1994)-, no que diz respeito às diferentes interpretaçóes dos atores envolvidos, das políticas públicas geradas, e das iniciativas físicas e de suporte digital implementadas, isto é, valorizando os processos sociopolíticos envolvidos em cada cidade, e respeitando a abordagem da teoria da construção social das tecnologias, como destacado anteriormente.

Este artigo divide-se em quatro partes principais, sendo a primeira uma breve discussão dos desafios colocados ao planejamento e governança urbanos em função da gradativa fragmentação das atividades de intervenção no território urbano e da constante dificuldade em acompanhar o ritmo das evoluções tecnológicas na cidade. Sustenta-se a ideia de fundo do artigo, sobre a maneira como as TICs podem e vêm influenciando as formas de apropriação do espaço e a gestão das cidades. Segundo, a partir de uma breve caracterizaçáo da importância de compreensão do desenvolvimento urbano-tecnológico, observamos casos concretos de quatro cidades médias, sendo duas no Brasil, uma na Bélgica e outra no Reino Unido, com o objetivo de compreender a maneira com que urbanistas e governos locais enfrentam os novos desafios, na tentativa de construção de uma abordagem integrada entre avanço tecnológico, planejamento e gestão urbana. Com base na teoria da construção social das tecnologias, a terceira parte empreende uma análise comparativa dos quatro estudos de caso. Finalmente, nas consideraçóes finais, busca-se uma síntese para melhor compreender o desafio do planejamento das cidades do futuro.

\section{Invisíveis e rápidos: novos elementos da cidade, velhas formas de planejar e gerir}

Como será possível perceber na descrição que faremos dos casos a seguir, uma das maiores dificuldades impostas pelas Tics a urbanistas e gestores urbanos é a facilidade com que estas se 'infiltram' no meio construído (por seu tamanho cada vez mais reduzido, e suas características cada vez mais próximas do invisível à visão humana), tornando-se, no termo da teoria da construçáo social das tecnologias, 'caixas pretas'2 (Bijker \& Law, 1997; Callon, 1989; Latour, 2005). Mark Weiser (1991) corrobora esta observação ao afirmar que "as mais profundas tecnologias

2 O termo "caixa preta" (do original black box), é comumente utilizado nos estudos sobre ciência, tecnologia e sociedade (ст)) para designar o desinteresse ou falta de informação sobre as redes sociais, econômicas, políticas e culturais que caracterizam uma tecnologia. O simbolismo ou significado de uma determinada tecnologia torna-se tấo difundido e aceito que não se presta atenção aos detalhes de seus elementos caracterizadores. Bruno Latour (2005) amplia essa noção em sua Teoria Ator-Rede (Actor-Network Theory) ao considerar que a idéia de caixa preta aplicase a elementos humanos e não-humanos (chamados actantes). 
são aquelas que desaparecem. Elas misturam-se ao tecido da vida cotidiana até tornarem-se indistintas"3 (p. 19).

Tendo em conta que grande parte dos estudos urbanos tradicionalmente se apoia em 'fisicalidades' - coisas visíveis e tangíveis como o espaço concreto e sistemas clássicos de infraestrutura- a invisibilidade parece ser um desafio elementar incorporado aos paradigmas que sustentam a organização contemporânea do espaço (Shiode, 2000). Consequentemente, impóe-se um grande desafio atual às atividades de planejamento e governança (Bonnett, 1999) na árdua transição, ainda em curso, da cidade industrial moderna - com regras e métodos rígidos de controle do espaço -para a cidade em redes pós-moderna- com predominância de elementos móveis, efêmeros, rápidos e invisíveis, mesmo que estes coexistam com estruturas sociopolíticas tradicionalmente hierarquizadas e antagônicas, aparentemente perenes.

As dificuldades em precisar os efeitos de infraestruturas associadas às TICs tornam suas relaçóes com as cidades e seus habitantes um fenômeno duvidoso e incerto, do ponto de vista teórico e empírico. Gestores urbanos têm sérias dificuldades em especificar as características particulares dessa fase atual de desenvolvimento do espaço urbano, da cidade em rede. Isso vale, sobretudo, para urbanistas e planejadores urbanos, uma vez que aspectos positivos ou negativos de um parque, uma ponte, uma rodovia ou de conjuntos habitacionais, costumam ser sempre muito visíveis e facilmente notados, sendo prática costumeira, por exemplo, a determinação dos impactos ambientais, sociais e econômicos de tais infraestruturas.

Ao contrário, as infraestruturas mais sofisticadas associadas às TiCs (como satélites, radares, geradores de ondas de rádio, etc.) e, principalmente, os fluxos produzidos por essas estruturas (micro-ondas, sinais eletromagnéticos e informação), são normalmente silenciosos e invisíveis para a maioria da população -acostumada com os aspectos visíveis e ruidosos da cidade industrial. A invisibilidade destes fluxos informacionais e comunicacionais, sustentadores dos processos político-administrativos, representa um desafio para a democracia e as práticas habituais da política, na medida em que os processos de influência e articulaçáo político-administrativa ocorrem crescentemente mediados pelas tecnologias e privados de controle público e democrático.

Do mesmo modo, o aproveitamento do potencial de democratização e horizontalização das estruturas de interação político-administrativa, inerente ao uso crescente das tics no setor público, apesar da progressiva disseminação de boas experiências na área (Kaufman, 2007; Frey, 2005), ainda fica bem aquém das possibilidades democratizantes abertas pelas novas tecnologias (Frey, 2009).

A conseqüência da fragmentação e reconfiguração de forças intra-administrativas pode ser, de um lado, uma falha na compreensáo da cidade à luz das transformaçóes potencializadas pelo desenvolvimento das tics e, por outro lado, uma negligência dos urbanistas, tradicionalmente predominantes no planejamento das cidades, em creditar a importância necessária dos aspectos de ordem social, política e cultural às relaçóes presentes num espaço urbano em constante transformaçáo. 
A cidade contemporânea traz consigo novos elementos que necessitam ser considerados na organização e reprodução do espaço urbano, formando o que podemos chamar de cidade ampliada. Este conceito fornece um arcabouço teóricoexplicativo para a relação, cada vez mais próxima, entre três elementos fundamentais constituintes da experiência humana no espaço urbano contemporâneo, quais sejam: tecnologias cada vez menores e mais invisíveis, que tendem a mesclar-se com o ambiente construído tradicional; um consequente aumento de nossa capacidade comunicacional (suportada por este grupo de tecnologias imperceptíveis: redes, Internet, celulares, etc.); e uma análoga ampliação das próprias características funcionais do espaço e da cidade. Em outras palavras, o conceito trata de uma ampliação do espaço urbano para além de suas limitaçôes físicas, proporcionada por uma capacidade estendida de comunicação e conexão, a partir do uso das TICs (Duarte \& Firmino, 2009; Aurigi \& De Cindio, 2008).

Urbanistas e profissionais do urbanismo ainda estão tentando se aproximar desse esforço coletivo de compreensão do mundo contemporâneo. Autores como Koolhaas e Mau (1995) mantém que novos métodos, instrumentos, organizaçáo e, na verdade, um novo urbanismo, deve emergir para lidar com a complexidade, flexibilidade e novos conceitos inerentes do espaço urbano contemporâneo. Num contexto em que o planejamento físico do desenvolvimento urbano se vê forçado a 'ceder espaço' às áreas soft da gestáo urbana, relacionadas primordialmente ao desenvolvimento cultural, social e econômico, em que a infraestrutura tecnológico-informacional ganha preponderância na gestão e no planejamento e em que, finalmente, é exigida uma nova sensibilidade frente às diferenças de necessidades existentes na sociedade urbana, este novo urbanismo passa, necessariamente, pela interdisciplinaridade na governança local e pela necessidade de ajustamento dos processos democráticos (Ascher, 2004).

O pano de fundo para nossa análise das práticas de planejamento urbano-tecnológico nos casos estudados é, assim, representado pela cidade contemporânea, com sua elevada complexidade em relação às diferentes dimensóes do desenvolvimento e, consequentemente, as crescentes exigências a uma governança compartilhada, no contexto da cidade ampliada, onde espaços são imbuídos de capacidades computacionais e comunicacionais, suportadas por tecnologias 'infiltradas' no ambiente construído tradicional.

\section{Desenvolvimento urbano-tecnológico: dilemas na busca por integração}

Vários estudos (Graham \& Dominy, 1991; Spectre, 2002a, 2002b; Aurigi, 2005; Firmino, 2005) apontam que poucas cidades têm considerado, de maneira consciente, o relacionamento entre o desenvolvimento urbano e as TICs. As preocupaçóes descritas na seção anterior raramente se incluem na pauta de discussóes e decisóes de gestores públicos na escala do município. Entretanto, a relação entre o planejamento e as questóes do desenvolvimento urbano-tecnológico não configura algo novo ou desconhecido, pelo menos do ponto de vista da construção social das tecnologias. Cidades e tecnologias já foram tratadas como parte de um fenômeno sócio-técnico por Aibar e Bijker (1997) no trabalho "Constructing a city: the Cerdà 
plan for the extension of Barcelona”, em que analisam o planejamento urbano pelas lentes sócio-construtivistas.

Ao considerar a abordagem de urbanistas e autoridades municipais com relação às TICs em uma perspectiva histórica, os autores encontraram evidências de uma dissociação entre as esferas social, econômica, espacial e tecnológica. O espaço era raramente considerado como um evento social em si próprio, inter-relacionado com todos os outros aspectos da sociedade; tampouco eram as tecnologias vistas como produto de articulaçóes sociais. Isso criou uma lacuna metodológica e conceitual no desenvolvimento das tecnologias nas cidades.

Com a intenção de tentar compreender essa lacuna, ao menos em parte, especialmente do ponto de vista da construção social das tecnologias, a seguir, discutiremos dois tipos distintos de abordagens urbano-tecnológicas: nos primeiros casos das cidades de São Carlos (Brasil) e Newcastle (Reino Unido), as estratégias administrativas são conservadoras e caracterizadas por uma atuação político-administrativa fragmentada no âmbito da governança eletrônica, ao passo que no segundo tipo de experiência, que incluem as cidades de Catanduva (Brasil) e Antuérpia (Bélgica), observou-se um maior alinhamento entre as estratégias de expansão tecnológica, as abordagens de reforma administrativa e a perseguição de propostas inovadoras de transformação e intervenção no espaço urbano.

Antes, porém, faz-se necessário alguns esclarecimentos metodológicos sobre as pesquisas realizadas nessas quatro cidades. Todas as cidades foram pesquisadas obedecendo a mesma metodologia de estudo de caso, mas respeitando um agrupamento por períodos separados. As quatro cidades foram foco de pesquisa com levantamentos no período de 2003 à 2006. Em todos os casos, as cidades foram selecionadas a partir de um levantamento inicial de universos semelhantes de cidades médias proativas na utilização de TICs para o planejamento e gestáo urbanas.

$\mathrm{Na}$ Europa, as cidades foram selecionadas de um universo de 122 municípios que à época participavam do consórcio TeleCities ${ }^{4}$ (fundado em 1993 e mantido pela Comunidade Europeia). No caso dos municípios brasileiros, foram selecionadas as duas cidades médias de maior destaque dentre as 300 cidades mais dinâmicas do Brasil segundo levantamento realizado pela Gazeta Mercantil em 2005 (Gazeta Mercantil, 2005). Os estudos de caso obedeceram a os mesmos critérios e foram realizados a partir da construçáo de protocolos de pesquisa conforme sugerido por Yin (1994), abrangendo a reunião de documentos, levantamento de projetos, organizaçóes administrativas, pessoas e grupos sociais, interesses, visóes e discursos a partir de entrevistas semiestruturadas e depoimentos à imprensa.

Em todos os casos, foram entrevistados gestores ou funcionários dos governos locais em cargos idênticos ou análogos (em geral nos primeiros três escalóes do governo). A coleta e avaliaçáo de dados privilegiou a busca de informaçóes correspondentes aos seguintes elementos de análise: a) todo e qualquer projeto público que faça uso ou se relacione às tecnologias telemáticas; b) métodos e práticas (políticas, institucionais e técnicas) através das quais esses projetos são concebidos, 
desenvolvidos, colocados em prática e mantidos; c) o ambiente político-administrativo das cidades onde esses projetos são postos em prática; d) o envolvimento do setor de planejamento urbano com esses projetos; e) as políticas públicas sobre as quais se dá a implementação de tais projetos; f) as motivaçóes e razóes para o desenvolvimento (ou não) dessas iniciativas; g) os diferentes grupos interessados na promoção desses projetos; h) e, principalmente, a existência ou não de uma estratégia estatal relacionada às questóes urbanas afetadas pelas tecnologias telemáticas.

Neste artigo, privilegiamos as discussóes sobre as semelhanças e diferenças entre os casos, do ponto de vista da organizaçáo e desenvolvimento dos projetos e, especialmente, sobre os principais dilemas envolvidos nas tentativas de implementação de estratégias de integração urbano-tecnológicas. Assim, optamos por breves descriçóes sobre cada caso, o agrupamento dos casos de acordo com as características político-administrativas de criação e gestão de seus projetos, e uma parte final, com explicaçóes mais detidas sobre as razóes desses agrupamentos, semelhanças e diferenças nos projetos e cidades.

Dessa forma, os relatos abaixo obedecem a um agrupamento com foco na estratégia geral das cidades, com relação ao uso e implementação de projetos relacionados às TICs. Foi possível identificar semelhanças marcantes na maneira como as cidades se organizam, institucionalmente e com relação à criaçáo e manutenção de projetos, obedecendo duas situaçóes extremas básicas: por um lado, com a apresentação de projetos interessantes e que fazem uso de TICs, porém sem apresentar uma estratégia integradora na estrutura do governo para lidar com as questóes relacionadas às tecnologias e sua influência no desenvolvimento urbano; e, por outro lado, cidades com projetos e estratégias convergentes no sentido da formação de uma visão central do governo local para as questóes urbano-tecnológicas. Em todos os casos, há uma busca pela maior integraçáo de projetos e esforços no sentido de se construir uma estratégia. Entretanto, essa busca se dá por caminhos distintos, ora pelas descentralizaçáo, ora pela centralizaçóes das açóes do governo na coordenação dos projetos. Foi possível agrupar, assim, as cidades de São Carlos (Brasil) e Newcastle (Reino Unido) segundo o padrão descentralizado, enquanto Catanduva (Brasil) e Antuérpia (Bélgica) respondem por padróes mais centralizadores nas açóes envolvendo as TICs.

Essa diferenciação se deu, principalmente, pela percepção da atuação de projetos 'guarda-chuva', ou estruturas administrativas ou institucionais que respondessem pela função integradora de projetos diversos envolvendo as Tics. A ausência de iniciativas desse tipo, foi considerada como atuação descentralizada, situação em que os projetos ocorrem mas sem que haja, necessariamente, uma conexáo central entre todos eles. Assim, no caso de Sáo Carlos e Newcastle, náo foi possível encontrar um projeto central ou uma estrutura que provesse a coordenação geral dos projetos envolvendo TiCs. Por outro lado, a cidade de Catanduva apresentou um projeto chamado Cidade Digital que tinha como uma de suas principais funçóes, abrigar todas as iniciativas relacionadas às TICs, enquanto Antuérpia mantinha um órgáo administrativo municipal (Telepolis), responsável por todas as açóes nesta área.

A seguir, traçamos um paralelo nessas comparaçóes entre as quatro cidades, fornecendo detalhes de projetos ou na organização destes, sempre que possível. 


\section{Integração pela atuação descentralizada:}

os casos de Sáo Carlos (Brasil) e Newcastle (Reino Unido)

Newcastle é uma cidade caracterizada pela luta das autoridades locais, agências de desenvolvimento e da população contra os índices de desemprego e queda da qualidade de vida que afetam toda a região nordeste do país, desde a década de 1980 até os dias de hoje. Em tempos recentes, como na maioria das cidades da região, a economia em Newcastle foi dominada pela indústria pesada, especialmente pelas atividades de mineração e construção de embarcações. Essa dependência da economia local da indústria pesada, teve grande influência na imagem da cidade e na confiança dos cidadãos, na habilidade das autoridades em reverter a crise econômica regional, seguida pelo declínio industrial. A partir dos anos 2000, Newcastle entrou com entusiasmo nas disputas por vantagens competitivas para atração de pessoas e empresas a se instalarem na regiáo, com ênfase especial no incentivo à atração de empresas limpas e de base tecnológica. A história de Newcastle na última década tem sido impulsionada por esse aspecto de reconstrução de sua imagem, o que é refletido na maneira com que as TICs sáo incorporadas no desenvolvimento urbano, com a clara tendência atual para projetos de regeneração urbana. Outra influência significativa na maneira com que as TICs se inseriram nas práticas administrativas se deu através da concepção da chamada 'terceira via' (Giddens, 1996), adotada pelo Labour Party em uma denominaçáo mais recente conhecida como New Labour (que dominou o cenário político no nordeste da Inglaterra por um longo período), seguindo o perfil de conciliação do modelo gerencial de administraçáo pública (New Public Management) com preocupaçóes de justiça social.

As tentativas constantes de se reconstruir a imagem da cidade caracterizam, claramente, os discursos de regeneraçáo urbana ou renascimento urbano que, por sua vez, se torna forte motivação para a implementaçáo de iniciativas ligadas às TICs. Este sentido de renovaçáo vem da premissa de desenvolvimento econômico de que Newcastle deve se livrar da imagem de uma antiga cidade industrial, deprimente e com baixa qualidade de vida, e substituí-la pela imagem de uma nova cidade alinhada com os desafios característicos do século Xxi.

Enquanto as autoridades locais em Newcastle tentam reconstruir uma imagem atrás da outra (de cidade da mineração e indústrias pesadas para cidade de festas nos anos 70-80, e agora como centro da cultura e tecnologia), a jovem cidade de São Carlos (com seus 150 anos) já tem uma tradiçáo de meio século de ser caracterizada como a capital brasileira da tecnologia. São Carlos, é de fato conhecida por abrigar campus de duas das principais universidades do Brasil (Universidade de Sáo Paulo [usp] e Universidade Federal de Sáo Carlos [ufscar]) e outros centros de pesquisa importantes (como a Embrapa). Isso se reflete em algumas estatísticas que apontam para a incrível marca de um pesquisador-doutor para cada 179 pessoas vivendo na cidade $^{5}$, tendo uma população de pouco mais de 200 mil habitantes (segundo o senso de 2010 do Instituto Brasileiro de Geografia e Estatística [IBGE]). A cidade ainda conta com dois parques tecnológicos, criados em 2010 (com incentivos do governo estadual que, em 2005, criou um programa chama Sistema de Parques

Dados da Prefeitura Municipal de São Carlos. 
Tecnológicos do Estado de São Paulo). A ideia de divulgar a cidade como a capital da tecnologia surgiu na década de 1980, com a criação, na cidade, da primeira incubadora de empresas de base tecnológica do Brasil. As autoridades locais têm adotado esta imagem desde então. Assim, a estratégia de construção de imagem dessas duas cidades seguem um mesmo padrão e, coincidentemente no mesmo período, apesar das diferenças contextuais.

Os discursos da regeneração urbana na Inglaterra ganharam força, também, nos anos 1980 e 1990, visando esforços para 'reconstrução' de centros urbanos e rearranjos referentes às economias locais. As ideias presentes nas propostas de regeneração urbana trouxeram um sentimento profundo de renovação ao país. As TICs se revelaram grandes fatores motivadores para os projetos de regeneração urbana implementados em muitas cidades inglesas, assim como para tentativas de se reconstruir imagens de cidades industriais tradicionais em declínio, podendo ser interpretadas como vetores de profundas mudanças nas economias locais. $\mathrm{O}$ uso 'propagandístico' das Tics é evidente em grande parte dos discursos e percepçóes dos principais atores locais em ambos os casos, como visóes atreladas ao desenvolvimento urbano e às reformas administrativas, com o intuito alegado de aumento da eficiência e a ampliação da participação cívica na condução da coisa pública.

As TICs têm sido entusiasticamente exploradas como vantagem competitiva por várias cidades ao redor do mundo e, da mesma forma, autoridades em Newcastle e Sáo Carlos adotaram o discurso 'pró-tecnológico'. De fato, tornou-se um fenômeno onipresente, nas cidades de hoje, as TICs figurarem como peças centrais de um jogo de aclamação local, muitas vezes acompanhado do imperativo da cidade-empresa ou da necessidade de 'limpeza' ou modernização da máquina administrativa, nos moldes da abordagem gerencial de administração pública.

Em Newcastle, este ímpeto avança nos dias de hoje sob o guarda-chuva da iniciativa Going for Growth (algo como 'a caminho do crescimento'). Sáo exatamente as idéias de renovação, renascimento e regeneração que estão na base dessa estratégia de modernizaçáo econômica e tecnológica que os diferentes governos da cidade perseguiram nos últimos anos. As TICs representam uma pequena, mas crescente parte da estratégia e os projetos ligados a essas tecnologias estão pulverizados em várias iniciativas e unidades do governo local. Esses projetos e visóes estão também refletidos na maneira fragmentada com que o governo local implementa as TICs através de suas seis secretarias. Com exceção de grandes projetos transversais como o Going for Growth, em geral, os projetos são definidos e geridos isoladamente em cada secretaria ou departamento. Os projetos relacionados às Tics náo divergem deste padrão. Isso significa que grande parte dos projetos são desenvolvido sem a devida atenção dada à interação mútua das unidades administrativas.

$\mathrm{Na}$ sua tentativa de gerar uma visão abrangente e integrada do desenvolvimento de projetos envolvidos com as TICs, o governo local implementou o E-services Panel, um tipo de órgáo colegiado interinstitucional de apoio às reformas administrativas relacionadas a e-governança. Entretanto, as análises e deliberaçóes deste 'conselho' tendem a seguir fatores de ordem econômica e ignorar outros aspectos como sociais, culturais ou mesmo espaciais, assim como a por depender de prioridades definidas por outros departamentos na estrutura organizacional da cidade. 
São Carlos mantém uma lista de dezesseis secretarias e departamentos em sua estrutura administrativa, tendentes à fragmentação da ação administrativa na realização dos projetos setorializados e pouco integrados, apesar de todos os esforços para uma coordenação central.

A tentativa de coordenação e integração mais destacada na cidade é um programa que se alimenta de reunióes periódicas do secretariado e dos grupos de trabalho de um lado, e de um sistema informatizado de acompanhamento de açóes e projetos de outro (SAOP), o que se assemelha, de alguma forma, ao E-service Panel de Newcastle, com a diferença de que, em São Carlos, o acompanhamento não é exclusivamente centrado nas tics. Ainda assim, a cidade mantém sua unidade tecnológica -Diretoria de Logística e Tecnologias da Informação (DLTI) - responsável pela construçáo técnica da maioria das iniciativas ligadas às TICs, entretanto, sem gozar de autoridade para o planejamento de açóes mais abrangentes e transversais.

Isso não quer dizer que as autoridades, em São Carlos, não estejam cientes da importância das Tics para a governança e para o planejamento, mas apenas que as açóes são implementadas de maneira fragmentada ou pulverizada o que, por sua vez, tende a diminuir a abrangência das iniciativas para solucionar os problemas mais complexos da cidade. O exemplo mais claro disse veio da existência do Departamento de Informação, Documentação e Patrimônio que, ao invés de figurar como unidade central na estrutura da administraçáo como um todo, está parcialmente isolado como anexo da Secretaria Municipal de Habitação e Desenvolvimento Urbano (SMHDU).

Em ambos os casos, de São Carlos e Newcastle, a estrutura administrativa da cidade segue o modelo de distribuição em 'silos', de maneira que os recursos são verticalmente distribuídos entre as várias secretarias e departamentos, e os projetos seguem a lógica prevalecente em cada unidade administrativa. Não há, em ambos os casos, um orçamento global especificamente direcionado para uma política institucional de governança eletrônica, como também não há estratégias administrativas integradoras, capazes de reorientar a própria atuação político-administrativa, em consonância com as possibilidades tecnológicas.

Ambas as cidades apresentam projetos interessantes do ponto de vista da utilização de TICs, sem, no entanto, promover integração na maioria dos casos (Firmino, 2004). Tanto em Newcastle como em Sáo Carlos, à época do estudo, foi possível encontrar diversos projetos setoriais nas áreas de: educação; treinamento e cultura; desenvolvimento econômico; administraçáo pública e infraestrutura; e acesso público às TICs.

Recorrendo a Lawson (1998) -que diferencia uma 'visão fraca' de governança eletrônica, isto é, uma abordagem essencialmente conservadora, que evita mudanças mais profundas na maneira com que o governo opera e funciona, de uma 'visáo forte', em que "a mudança da forma como o governo opera e dos serviços que presta está de mãos dadas com a transformação de sua cultura, abordagem e estrutura" (Lawson, 1998, p.16)-, podemos constatar a inexistência de uma vinculação entre a política institucional de expansão do uso das TICs, a reforma administrativa e a prestaçáo de serviços públicos por meios eletrônicos, e novas abordagens de intervençáo no espaço urbano, além de carecer de um envolvimento da sociedade civil na formulação e implementação das propostas, evidenciando portanto, uma visão e prática fracas de inovação tecnológica. 
A recente história da abordagem de TICs e sua simbologia, enquanto vantagem competitiva na atraçáo de investimentos, aponta nas duas cidades analisadas, para uma continuidade do uso dessas tecnologias como parte de estratégias orientadas, meramente, para os negócios e as atividades empresariais, ignorando, destarte, sua potencial contribuição para a democratização dos processos sociopolíticos nas cidades.

Integração pela coordenação centralizada: os casos de Catanduva (Brasil) e Antuérpia (Bélgica)

Antuérpia é uma das maiores cidades da Bélgica, com um quarto da população flamenga, e está estrategicamente posicionada em um dos cantos do chamado 'diamante flamengo', no norte do país. Além de sua importância econômica para a regiáo do Flandres e para a Bélgica, a cidade tornou-se também sinônimo europeu de inovação e de sucesso no uso de Tics, sendo um dos membros fundadores da mesa diretora do consórcio de cidades TeleCities. Trata-se, sem dúvida, do caso mais avançado na Bélgica a fazer uso extensivo das Tics na administração pública e no desenvolvimento urbano. As autoridades locais na Antuérpia consideram as TICs um dos vetores centrais de desenvolvimento urbano, e, para isso, criaram a agência Telepolis, responsável pela coordenação, uso e implementação de iniciativas ligadas às TICs na cidade e região, pela modernização do governo local, pela manutençáo da infraestrutura e contratos de TICs, e pela elaboração de políticas públicas e açóes específicas de desenvolvimento urbano-tecnológico (Firmino, 2004).

Catanduva, apesar de não representar nem um destaque econômico e estar cercada por cidades maiores e mais importantes no estado de São Paulo, é bem situada no coração do estado mais desenvolvido do país, fazendo parte de uma importante rede de mais de 50 cidades médias bem desenvolvidas e estruturadas para os padróes latino-americanos. Talvez, exatamente por seu tamanho reduzido, a cidade tenha recebido atenção da mídia, entre os anos 2004 e 2006, como caso de sucesso na implementação de iniciativas relacionadas ao governo eletrônico, inclusão digital, integração administrativa, rede sem fios pública, e outros projetos semelhantes. Mesmo em uma proporção menor e sem a mesma força dos resultados das políticas abrangentes da Antuérpia, as autoridades locais de Catanduva delegaram certos poderes à Diretoria de Informática (DI), parte da Secretaria de Planejamento e Informática, para criar e disseminar iniciativas transversais envolvendo as Tics.

$\mathrm{Na}$ Antuérpia, o inovador desenvolvimento de iniciativas de TICs - particularmente de infraestrutura - foi altamente influenciado pela reestruturação política e administrativa dos governos locais na Bélgica. O processo de devolução de poder político-administrativo ao nível regional do começo dos anos 80 , impulsionou um intenso processo de introdução das TiCs na administração urbana, pela simples necessidade de se administrar a fusão de nove localidades vizinhas na formação da atual cidade da Antuérpia. Com essa fusão, a estratégia política adotada pelas autoridades locais foi a da descentralização dos serviços públicos em nove distritos ou subprefeituras, o que contribuiu para diluir, durante os anos 1990, o crescente poder local do partido de extrema direita, Vlaams Blok. 
$\mathrm{O}$ arrojo das autoridades em Catanduva veio de uma situação muito mais peculiar no final do ano de 2004, quando o, entâo, recém-eleito prefeito decidiu formar um pequeno grupo de assessores especiais, que viria a compor um corpo informal chamado de Núcleo de Gestáo Estratégica (NGE), tendo como tarefa principal conceber uma estratégia para os quatro anos de governo, promovendo integração e eficiência da agenda de açóes do executivo municipal. Através da criação do projeto guarda-chuva Catanduva Cidade Digital, era lançada uma série de iniciativas relacionadas à disseminação das TiCs e dirigidas a diferentes objetivos específicos, transformando as tecnologias em meios para atingi-los, ao invés de fins em si mesmas.

As TICs serviram também como instrumento integrador na Antuérpia devido a sua contribuição na melhoria da comunicação entre os diversos departamentos da cidade e suas subprefeituras. Telepolis pode ser considerada o resultado físico e de cooperação institucional do processo de evoluçáo da abordagem urbano-tecnológica integrada na Antuérpia, o que deu à cidade um diferencial estratégico na própria perseguição das reformas político-administrativas e territoriais consideradas fundamentais para o processo de desenvolvimento da cidade. Trata-se, entre os casos estudados, de uma experiência única de uma forte e independente unidade de governo criada especificamente para lidar com as questóes relativas à promoçáo das Tics no âmbito de uma estratégia institucional de transformação político-administrativa, integrando a modernizaçáo tecnológica com a busca de novos modos de atuaçáo governamental. Não obstante, em graus diferenciados os dois casos se aproximam, portanto, à visão forte de governança eletrônica na acepção de Lawson (1998), citada anteriormente.

Em ambos os casos, criatividade e arrojo administrativo proporcionaram o surgimento de estruturas governamentais responsáveis para a promoção das Tics. No caso da Antuérpia, isso se deu de forma mais sólida por meio de uma agência municipal, enquanto no caso de Catanduva, a dependência em um projeto guardachuva e uma diretoria de segundo escalão, produzia um resultado mais efêmero e dependente das vontades políticas dos governantes subsequentes. Em ambos os casos, todos os projetos desenvolvidos no período estudado respondiam, hierarquicamente, à estrutura central criada para lidar com os assuntos envolvendo as TICs. A coincidência entre esses dois casos e os anteriores, reside nos tipos de projetos desenvolvidos. Isto é, independente da forma com que os projetos eram criados e geridos, suas aplicaçóes tinham direcionamentos semelhantes em todos os quatro casos, repetindo suas áreas de influência. $\mathrm{O}$ caso da Antuérpia apresenta ainda um diferencial não encontrado em nenhuma outra cidade estudada, que foi a existência, internamente à agência Telepolis, de um think tank especificamente designado para pensar as inovaçóes tecnológicas na cidade no médio e longo prazos. Este grupo era formado por alguns funcionários da própria agência, que se reuniam com frequência para discutir e propor tais inovaçóes.

Independentemente dos resultados específicos e da idade das iniciativas nos dois casos, Telepolis na Antuérpia de um lado, e o DI com seu projeto de cidade digital em Catanduva de outro, formam a espinha central de uma estrutura de coordenação para planejar e gerir estratégias de longo prazo para o desenvolvimento urbanotecnológico nessas duas cidades. Assim, tanto na Antuérpia como em Catanduva, alguns grupos sociais relevantes visualizaram as funçóes e potencialidades das TICs 
como meios de dar sustentação, respectivamente, às reformas político-administrativas na Bélgica, e de auxiliar na integração e no fortalecimento das estruturas político-administrativas locais, tradicionalmente muito fragmentadas no Brasil. Portanto, nos dois casos, grandes esforços foram feitos na tentativa de se estabelecer uma estratégia urbano-tecnológica sólida e integrada, apesar dos cenários regionais e nacionais totalmente contrastantes.

\section{A construção sociopolítica do desenvolvimento urbano-tecnológico: uma análise comparativa}

Podemos distinguir pelo menos três fatores importantes para a compreensão das particularidades das estratégias urbano-tecnológicas adotadas pelas diferentes cidades e que precisam ser levados em consideração na análise dos papéis do planejamento e da governança nos processos de desenvolvimento urbano apoiados pelas Tics: a flexibilidade interpretativa; o contexto particular; e a abordagem urbano-tecnológica.

\section{Negociando visóes:}

A importância da flexibilidade interpretativa e as estruturas de poder

Flexibilidade interpretativa representa um dos mais influentes dilemas e desafios enfrentados pelas autoridades locais, na medida em que tentam desenvolver estratégias de desenvolvimento urbano-tecnológico (Firmino, 2004). Ao mesmo tempo em que a contemplação de uma pluralidade de visóes é benéfica para a construção democrática das propostas e iniciativas, é difícil a tarefa de lidar com elas e traduzi-las em uma estratégia integrada. Ademais, é importante lembrar que o processo de formação dessas estratégias é um complexo fenômeno social e político, envolvendo inúmeras partes e variáveis. A ampla variedade de visóes sobre iniciativas ligadas às Tics, pelos diferentes setores, é crucial na definição das abordagens locais.

Podemos observar contradiçôes interessantes, nos casos de Newcastle e Sáo Carlos de um lado, e Antuérpia e Catanduva de outro. Por um lado, os aspectos dominantes nos discursos dos atores principais, nas quatro cidades, apresentam grandes semelhanças no seu conjunto (o que define as principais tendências de aplicação das TICs), apesar de divergências interpretativas, e discursos proeminentes em favor da regeneração urbana e modernização administrativa. Por outro lado, com relação às estruturas em que as iniciativas são desenvolvidas desde os estágios iniciais de negociação, as diferenças entre estes dois grupos de cidades são marcantes. Fragmentação e dispersão das iniciativas dominam a cena em Newcastle e Sáo Carlos, enquanto em Antuérpia e Catanduva prevalece uma abordagem mais integrada e centralmente coordenada.

Nos primeiros dois casos, os projetos são geralmente concebidos, planejados, financiados, implementados e mantidos independentemente, isto é, um departamento pode desenvolver um projeto ligado às TICs sem articular-se com outras unidades da administração. Dependendo da natureza do projeto, interaçóes eventualmente acontecem, mas apenas quando a unidade de origem do projeto necessitar a cooperação de outras. As inovaçóes tecnológicas são, primordialmente, impulsionadas pelas demandas específicas dos diferentes setores. 
Na Antuérpia e em Catanduva, tal interação acontece quase de maneira automática, já que Telepolis e o Di lideram quase $100 \%$ das iniciativas relacionadas com as TICs, na direção de uma integração de visôes. Há, assim, uma tendência ou um potencial de todas as iniciativas TICs desenvolverem-se de forma mais integrada, e considerando os diferentes interesses de atores dentre os servidores públicos, autoridades, diretores e funcionários das unidades dedicadas às TICs.

No entanto, o lado negativo dos casos de forte coordenação central -além dos próprios custos transacionais da coordenação- está relacionado ao risco desta centralidade suprimir a saudável multiplicidade de visôes com uma postura 'autoritária' de imposição central de iniciativas e projetos às unidades descentralizadas ou setoriais. Ademais, isso pode reforçar a tendência de exclusão da sociedade civil e dos cidadãos de decisóes sobre os caminhos tecnológicos a serem trilhados, uma vez que a interação com o público externo se dá, em geral, antes no nível das secretarias fins, ao passo que o etos tecnocrático que frequentemente prevalece em tais unidades de TI tende a afastar o público, ainda mais, de tais processos de inovaçáo tecnológica.

O êxito de projetos e iniciativas, portanto, também não está diretamente relacionado com o grau de descentralização ou centralização das estruturas de seu desenvolvimento, mas depende muito mais da maneira com que são individualmente desenvolvidos e implementados, sobretudo, do grau de diálogo entre as instâncias centrais e periféricas -como também com o público externo à burocracia-, mesmo que um certo grau de institucionalização de funçóes de coordenação e integração seja indubitavelmente imprescindível.

Considerando abordagem e estratégia para os quatro casos, o estudo empírico realizado permite identificar dois padróes que se sobressaem. Primeiro, na maneira fragmentada de desenvolvimento de açóes públicas dos casos de Newcastle e São Carlos, visóes para uma iniciativa específica são consideradas de maneira restrita a poucas unidades da administração. Interpretaçóes representando unidades diferentes tendem a não colidirem em seus caminhos até tornarem-se ações ou políticas públicas. Elas são 'canalizadas' desde os primeiros momentos nas unidades de origem, até a transformação em açóes e implementação, geralmente pela mesma unidade. Assim, a partir do momento em que um projeto é definido por certa unidade responsável por sua implementação, a tendência é a de que este não seja influenciado pelas visóes de outras unidades, devido á pouca integração entre elas. Evita-se, com isso, possíveis conflitos de interesse baseados em interpretaçóes diferenciadas, ao passo que chances de soluçóes integradas com maior potencial de sinergia passam despercebidas. Segundo, no caso do modelo de coordenação centralizada de Antuérpia e Catanduva, no que tange ao desenvolvimento dos projetos, ideias para novas iniciativas tendem a ser de responsabilidade das unidades dedicadas às TICs. O governo municipal e os outros departamentos precisam reportar-se a estas unidades em caso de certas demandas específicas ou problemas relacionados às TICs. As unidades dedicadas irão, então, através de seus técnicos e diretores, estudar os casos e promover novos desenvolvimentos. Mesmo que de um lado, este modelo centralizado fortaleça a dimensão da integração e coordenação, pode implicar, por outro lado, o descomprometimento das unidades setoriais com os desafios tecnológicos em função da implícita reconfiguração das relaçóes de poder intra-administrativas. 
Neste sentido, enquanto de um lado é incontestável a necessidade de estratégias administrativas capazes de incorporar a variedade de visóes e interpretaçóes, exigindo, portanto, certo grau de centralização, tornam-se imprescindíveis, de outro, mecanismos capazes de garantir a cooperação e o controle democrático por parte da sociedade como um todo, privilegiando desta maneira a descentralizaçáo. Ou seja, apenas no caso dos cidadãos e comunidades serem envolvidos na formulação de estratégias de governança eletrônica, permitindo inclusive a ampliaçáo do uso dos meios eletrônicos para influenciar a atuação dos governos, pode-se chegar a práticas transformadoras de e-governança capazes de mudar a própria natureza das sociedades. Todos os casos estudados ainda encontram-se distantes deste último estágio de e-governança (Ferguson, 2002).

\section{A importância de um contexto específico}

Outro importante fator de influência diretamente envolvido com a implementação das estratégias públicas, é o contexto regional e nacional das quatro cidades. Isso torna um estudo com comparaçóes internacionais mais complicados, mas valioso pelas análises e possibilidades de comparação.

De um lado, o sistema político e de gestão britânico, e de outro os sistemas belga e brasileiro, representam a grosso modo, dois opostos grupos de sistemas políticos em termos de centralizaçáo e descentralização do poder, ou, em outras palavras, em termos de autonomia delegada às autoridades locais.

O sistema britânico é altamente centralizado, prevendo a participação do governo central na definição de metas e políticas no âmbito municipal, garantindo os principais financiamentos das municipalidades e condicionando a distribuição destes recursos. Com a finalidade de manter um fluxo contínuo de investimentos do governo central - que representa quase a totalidade dos recursos - autoridades locais não têm opçáo senão seguir as estritas diretrizes determinadas por Downing Street (sede do governo britânico em Londres). Pouca flexibilidade é permitida, resultando no fato das autoridades locais funcionarem mais como representantes diretos do governo central, exercitando pouca autonomia. Os governos municipais e suas estratégias são fortemente amarrados ao que o poder central em Londres julgar melhor para suas localidades. Neste sentido, o papel preponderante das Tics como norteadoras dos processos de modernização em todas as repartiçôes públicas, se baseia em legislação nacional, impondo linhas de conduta e padrôes aos municípios na implementação das práticas de governo eletrônico (Ferguson, 2002).

Apesar das diferenças significativas entre o Brasil -uma federação de 26 estados e um distrito federal, com a divisão de poderes entre as esferas federal, estadual e municipal-e a Bélgica -também uma federação em três esferas de poder, mas com divisóes entre os governos federal, regional e linguístico- ambos os casos compartilham o fato de suas regióes e municipalidades exercitarem mais autonomia na decisão sobre suas açóes mais importantes, inclusive no que diz respeito ao desenvolvimento urbano-tecnológico. Na Bélgica, por exemplo, a cidade de Antuérpia tem sido autônoma o suficiente para decidir sobre sua própria configuração territorial, administrativa e política, com pouca interferência dos níveis superiores de governo. Os sistemas de planejamento na Bélgica e no Flandres permitem aos 
governos municipais decidirem sobre suas metas e políticas públicas desde que haja compatibilidade com as diretrizes genéricas para cada unidade territorial e para o país. Os casos brasileiros não são muito diferentes disso, dado que as açóes municipais não se opóem às constituiçóes estaduais e federal.

Resumindo, os níveis supra-municipais de governo, no Brasil e na Bélgica, tendem a não interferir nos meios pelos quais as autoridades municipais usam as TICs e perseguem suas metas, desde que em concordância com os planos estratégicos regionais e nacionais. No entanto, é preciso considerar as particularidades das culturas político-administrativas de cada um dos países ou cidades. Mesmo que todos os países em questão disponham de sistemas políticos democráticos, as possibilidades dos municípios fazerem valer suas competências em benefício de melhorias da sua população, dependem tanto das estruturas institucionais formais existentes como dos padróes informais de colaboração e cooperação. No Brasil, os vícios tradicionais de clientelismo, fisiologismo e autoritarismo muitas vezes implicam em uma falta de controle democrático por parte da sociedade civil, favorecendo a apropriação das vantagens, inerentes às reformas administrativas, por interesses privados.

Obviamente, essas diferenças entre os três países são muito importantes e influenciam na criação e gestão de estratégias urbanas, tendo que ser levadas em consideração, independentemente das semelhanças entre as açóes e projetos específicos.

\section{Iniciativas semelhantes, abordagens distintas}

Com relação às abordagens e estratégias adotadas, é importante destacar o fato das quatro cidades terem desenvolvido projetos muito semelhantes, pelo menos quando vistos isoladamente. Esses projetos incluem quiosques de rua, acesso a Internet e computadores em espaços públicos, esquemas de inclusão digital através de cursos subsidiados, modernização das estruturas administrativas e de gestão, unidade dedicada às TICs, e assim por diante. Mesmo quando náo acontecendo de maneira semelhante nos quatro casos, é possível encontrar projetos similares em grupos de, pelo menos, duas das cidades analisadas. Portanto, deve ser levado em consideração que as estratégias locais não se expliquem apenas a partir das condiçôes locais existentes, mas a progressiva globalização do discurso e das estratégias da governança eletrônica, reforçada pelas conferências nacionais e globais -como a Cúpula Mundial sobre a Sociedade da Informaçáo- como também do estabelecimento de redes de cooperação entre cidades e municípios relacionadas à propagaçáo das novas tecnologias, a exemplo da rede TeleCities da qual Antuérpia faz parte, que tendem a favorecer a uniformização das iniciativas de desenvolvimento urbano-tecnológico.

Olhar as iniciativas, isoladamente, não é suficiente para a compreensão da abordagem de cada cidade, o que se pode conseguir mais facilmente observando-se a maneira com que os governos municipais dessas cidades trabalham a integração de suas açóes e lidam com a multiplicidade de visóes, problematizaçóes, e buscas por soluçóes. A observação, desde este ponto de vista revela diferenças marcantes entre os dois grupos de cidades descritos acima (de açóes dispersas ou integradas) e as contradiçóes presentes em ambos. 
Mas o que se mostra ainda mais marcante em termos da estrutura geral do desenvolvimento urbano-tecnológico, é que a combinação de contextos políticos locais com a ausência ou presença de uma coordenação integradora, e ainda, a visão particular de grupos sociais em cada caso, em combinação, produziram basicamente quatro tipos diferentes de açóes e atitudes com relação ao uso de TiCs nas cidades; ou quatro tipos de visão, de acordo com a abordagem sсот, proposta no início do artigo. Isso parece corroborar o argumento que a integraçáo, apesar de ser importante enquanto facilitador de políticas públicas, sozinha não garante o sucesso ou a forma final de uma estratégia de desenvolvimento urbano-tecnológico. No final, isso dependerá de uma miríade de fatores que, juntos, formam o que chamamos de construção sócio-técnico do desenvolvimento urbano-tecnológico, em que contam não apenas as estratégias administrativas adotadas, mas todo o ambiente sociopolítico e sua influência nos processos de tomada de decisão.

Assim, primeiramente, uma estrutura política fortemente centralizada no nível de decisóes nacional no Reino Unido, juntamente com uma estrutura local de desenvolvimento de projetos e distribuição de recursos extremamente fragmentada e dispersa como em Newcastle, resulta em uma vaga, de fato, quase imperceptível estratégia urbano-tecnológica, caracterizada mais por atitudes de reação e de defesa, ou pela fragmentação em estratégias setoriais que sempre correm o risco de se contrariar ou, pelo menos, não explorar os possíveis ganhos sinergéticos de estratégias integradas. Este fato estabelece claras relações com as tendências apontadas no início do artigo, em que governos locais mostram-se despreparados para enfrentar os desafios impostos pelas TICs às cidades contemporâneas.

Segundo, em São Carlos, ao aproveitar a autonomia política relativa em suas decisôes, e apresentar um modo disperso de desenvolvimento de açóes e projetos, o governo municipal produziu casos interessantes de uso de TICs em iniciativas urbano-tecnológicas e na modernização administrativa, partindo quase do zero. Isso ocorre, principalmente, em função de um grupo privilegiado de visionários trabalhando no governo municipal, a maioria deles abertos a novas ideias e ao planejamento de estratégias de longo prazo.

Terceiro, no mesmo contexto político brasileiro e com uma abordagem de coordenação centralizada, integrando a gestão das Tics à agenda urbana -contando para isso com o DI e o abrangente projeto Cidade Digital- o governo municipal em Catanduva ultrapassou vários problemas na tentativa de colocar em prática seus projetos, devido a barreiras que vão desde limitaçóes orçamentárias a disputas políticas internas e externas. Cedo ou tarde, muitas das iniciativas acabam por vir à tona, apesar de nem sempre acontecerem como foram inicialmente e centralmente planejadas pelo DI. É importante alertar para o fato que no contexto brasileiro esse tipo de visão integrada ainda depende fortemente do empreendedorismo inovador de alguns prefeitos e governos, caracterizando-se, portanto como experiências isoladas e com pouca representatividade em termos nacionais.

Quarto, apesar de estar inserida em um contexto político nacional e regional descentralizado e complexo, na Bélgica, com seus diferentes níveis de poder territorial, cultural e linguísticos, uma estrutura altamente integrada e centralizada na figura da agência Telepolis define a estratégia de coordenação de projetos ligados às TICs e 
gestão de políticas públicas urbanas na Antuérpia. A consequência é uma abordagem integrada com uma atitude pró-ativa do governo municipal e da agência de Tics.

Finalmente, é evidente que essas quatro cidades representam casos exemplares de duas maneiras distintas de abordagem e compreensão das Tics, como parte da agenda das questóes urbanas (dispersas em Newcastle e São Carlos, e integradas na Antuérpia e em Catanduva). Esses casos também representam quatro maneiras diferentes pelas quais se dá a construção sociopolítica das TICs urbanas, ou a absorção e estabilização de um grupo de tecnologia da informação e comunicação no nível político local, vis-à-vis à estrutura social existente, a os sistemas políticos e administrativos, à base econômica local, às condiçóes históricas e circunstanciais, e às interpretaçóes e aspiraçóes de atores-chave com relaçáo a estes aspectos.

\section{Consideraçóes finais}

Neste artigo, discutimos uma combinação de conceitos e críticas destinados a uma nova interpretaçáo da cidade e de sua gestáo, no contexto atual, do avanço das novas tecnologias no espaço urbano. No entanto, não se trata de uma perspectiva de substituição dos elementos tradicionais do espaço, mas antes, da necessidade de adicionar novas dimensóes de interaçóes físico-virtuais, complementando as esferas de relaçóes sociais, culturais, políticas, econômicas e territoriais na sociedade contemporânea. Neste sentido, parece haver uma necessidade, do ponto de vista do planejamento e da gestão, que que se desenvolvam conceitos e métodos capazes de priorizar uma integraçáo entre o desenvolvimento do espaço e o desenvolvimento tecnológico, isto é, estratégias de desenvolvimento urbano-tecnológico.

No que diz respeito aos estudos de caso, como base de comparaçáo de quatro cidades em três diferentes cenários nacionais, é importante notar a similaridade entre elas com relação aos projetos individuais e alguns dos aspectos dominantes na visão e nos discursos de seus principais atores. Apesar dessas semelhanças, as estratégias gerais adotadas por seus respectivos governos locais revelaram-se bem distintas. Fragmentação de um lado e integração de outro, formam os resultados de relaçóes e combinação de elementos complexos como, por exemplo, o contexto político e administrativo de cada caso. Outra influência marcante foi a das circunstâncias históricas em que cada caso se desenvolveu. As motivaçóes iniciais, dos grupos sociais de cada caso também se mostraram relevantes.

O diferencial mais interessante entre as maneiras com que essas abordagens evoluíram para iniciativas e açóes, parece residir no modo com que diferentes interpretaçóes, visóes, expectativas e interesses são arranjados, negociados e geridos pelas autoridades locais. A sua incorporação em uma visão única (ou não), a integração delas (ou não), parece ser o fator de maior relevância na elaboração de estratégias urbano-tecnológicas. Flexibilidade interpretativa e estratégias urbano-tecnológicas, nesses casos, mostraram estar relacionadas à natureza das interpretaçóes e processos envolvidos com a gestáo de tais interpretaçóes, e com as relaçóes de poder que caracterizam as estruturas sociopolíticas.

Nos casos estudados de Newcastle, São Carlos, Antuérpia e Catanduva, as dificuldades de compreensáo das relaçóes complexas envolvidas com o desenvolvimento 
de tecnologias, comprometem potencialmente futuras açóes para o uso estratégico desses desenvolvimentos como parte das questóes urbanas e da agenda urbana. No caso mais proeminente, apesar das condiçóes particulares e históricas terem contribuído para a geração de uma visão estratégica dos desenvolvimentos tecnológicos na Antuérpia, a cidade ainda deixa escapar um componente urbano e espacial ao não incorporar, de forma sistemática, as TICs ao planejamento urbano. Em Catanduva, o DI é parte da Secretaria de Planejamento e Informática, mas ambas as partes não se inter-relacionam, enquanto as formas tradicionais de planejamento continuam sendo praticadas com pouca ou nenhuma integração com as questôes de TiCs.

Finalmente, é fundamental ressaltar que, independente do fato de privilegiar estratégias de centralização ou de descentralização na promoção das TICs, o êxito do desenvolvimento urbano-tecnológico depende da capacidade dos governos locais em promover discussóes e debates amplos, tanto interna quanto externamente à administração pública, envolvendo as comunidades locais, para que se garanta um mínimo de compreensão sobre os diversos aspectos dos impactos das TICs na vida urbana cotidiana; mas também, para que as demandas e expectativas populares possam ser efetivamente contempladas nas estratégias elaboradas e implementadas. Neste sentido, as próprias TICs precisam tornar-se instrumentos de participação política dos cidadãos e dos interesses organizados na formulação de estratégias de desenvolvimento urbano-tecnológico. oEURE

\section{Referências bibliográficas}

Aibar, E. \& Bijker, W. (1997). Constructing a city: the Cerdà plan for the extension of Barcelona. Science, Technology, \& Human values, 22(1), 3-30. doi: 10.1177/016224399702200101 Ascher, F. (2004). Les nouveaux principes de l'urbanisme. La Tour d'Aigues: L'Aube.

Aurigi, A. (2005). Making the digital city: the early shaping of urban Internet space. Aldershot: Ashgate.

Aurigi, A. \& De Cindio, F. (2008). Augmented public spaces: articulating the physical and electronic city. Aldershot: Ashgate.

Bijker, W. (1995). Of Bicycles, Bakelites, and bulbs: Toward a theory of sociotechnical change. Cambridge, MA: мIт Press.

Bijker, W. \& Law, J. (Eds.) (1997). Shaping technology/Building society: Studies in sociotechnical change, London: MIT Press.

Bonnett, T. (1999). Governance in the digital age. Public Management, 81(9), 6-14.

Callon, M. (1989). Society in the making: the study of technology as a tool for sociological analysis. Em W. Bijker, T. Hughes \& T. Pinch (Eds.), The social construction of technological systems: New directions in the sociology and history of technology (pp. 85103). Cambridge: міт Press.

Duarte, F. \& Firmino, R. (2009). Infiltrated city, augmented space: information and communication technologies, and representations of contemporary spatialities. Journal of Architecture, 14(5), 545-565. doi: 0.1080/13602360903187493 
Ferguson, M. (2002). Estratégias de governo eletrônico. O cenário internacional em desenvolvimento. Em J. Eisenberg \& J. Cepik (Orgs.). Internet e politica: teoria e prática da democracia eletrônica (pp. 103-40). Belo Horizonte: Ed. Universidade Federal de Minas Gerais (UFMG).

Firmino, R. (2004). Building the virtual city: the dilemmas of integrative strategies for urban and electronic spaces (Tese Doutorado), University of Newcastle, Newcastle.

Firmino, R. (2005). Planning the unplannable: How local authorities integrate urban and ICTs policy-making. Journal of Urban Technology, 12(2), 49-69. doi: $0.1080 / 10630730500307979$

Frey, K. (2005). Gobernanza electrónica urbana y inclusión digital: experiências en ciudades europeas y brasileñas. Nueva Sociedad, 196, 109-24. Disponible en http://www.nuso. org/upload/anexos/foro_474.pdf

Frey, K. (2009). Perspectivas da democracia local na era digital. Em: M. Cunha, K. Frey \& F. Duarte (Orgs.). Governança local e tecnologias da informação e comunicação (pp. 3150). Curitiba: Champagnat.

Gazeta Mercantil. (2005). Atlas do mercado brasileiro, Vol. 6. São Paulo: Autor.

Giddens, A. (1996). Para além da esquerda e da direita: o futuro da política radical. São Paulo: Universidade Estadual Paulista (UNESP).

Graham, S. \& Dominy, G. (1991). Planning for the information city: the uk case. Progress in Planning, 35, 169-248. doi: 0.1016/j.bbr.2011.03.031.

Graham, S. \& Marvin, S. (1996). Telecommunications and the city: electronic space, urban places. London: Routledge.

Kaufman, E. (Org.). (2007). Politicas públicas y tecnologías: líneas de acción para América Latina. Buenos Aires: La Crujía.

Koolhaas, R. \& Mau, B. (1995). Small, medium, large, extra-large: office for metropolitan architecture. New York: Monacelli Press.

Lawson, G. (1998). NetState: creating electronic government. London: Demos.

Latour, B. (2005). Reassembling the social: an introduction to actor-network-theory. Oxford: Oxford University Press.

Pinch, T. \& Bijker, W. (1989). The social construction of facts and artifacts: or how the sociology of science and the sociology of technology might benefit each other'. Em W. Bijker, T. Hughes \& T. Pinch (Eds.), The social construction of technological systems: new directions in the sociology and history of technology (pp. 17-50). London: MIT Press.

Santos, M. (1994). Técnica espaço tempo: globalização e meio técnico-científico-informacional. São Paulo: Hucitec.

Shiode, N. (2000). Urban planning, information technology, and cyberspace. Journal of Urban Technology, 7(2), 105-26. doi: 10.1080/713684111

Spectre. (2002a). Strategic planning guide - Dealing with ICT in spatial planning: a guide for practitioners. Province Noord-Holland: Haarlem.

Spectre. (2002b). Vision on ICT and space - vision on the relationship between information and communication technologies and space. Province Noord-Holland: Haarlem.

Van den Besselaar, P. \& Koizumi, S. (Eds.). (2005). Digital cities III: Information technologies for social capital - Cross-cultural perspectives. Berlin: Springer-Verlag.

Weiser, M. (1991). The computer for the 21st century. Scientific American, 265(3), 94-104.

Yin, R. (1994). Case study research: design and methods. California, CA: Sage. 